\title{
O ensino de História e a formação continuada de professores: por uma prática para além das amarras
}

\author{
Júlia Silveira Matos* \\ Adriana Kivanski de Senna**
}

Resumo: Os debates sobre a profissionalização do historiador estão em voga neste momento no qual tramita no Senado e na Câmara dos Deputados um projeto de lei que regulamenta a profissão de Historiador no Brasil. Nesse ínterim, no presente texto, analisaremos o papel das políticas de formação continuada de professores de História na profissionalização do historiador, considerando que a docência é o seu espaço privilegiado de atuação no campo de trabalho.

Palavras-chave: Formação de professores; Ensino de história; Profissionalização

Abstract: The debates about the professionalisation of the historian are in vogue at that time in which deal in the Senate and the House of Representatives a bill that regulates the profession of historian in Brazil. Meanwhile, in this text examine the role of policies continued teacher of history at the professional historian, considering that teaching is their special area of expertise in the field of work.

Keywords: Teacher training; Teaching history; Professional.

* Professora do curso de História da Universidade Federal do Rio Grande - FURG, doutora em História pela PUCRS. E-mail: jul_matos@hotmail.com

* Professora do curso de História da Universidade Federal do Rio Grande - FURG, doutora em História pela PUCRS. E-mail: adrianasenna@vetorial.net 


\section{À guisa de introdução}

Os debates sobre a profissionalização do historiador estão em voga neste momento no qual tramita no Senado e na Câmara dos Deputados um projeto de lei que regulamenta a profissão de Historiador no Brasil. Nesse ínterim, no presente texto, analisaremos o papel da formação continuada de professores de História enquanto base reflexiva para a profissionalização do historiador, considerando que a docência é o seu espaço privilegiado de atuação no campo de trabalho.

Conforme poema de Carlos Drumond de Andrade, o historiador é:

Figura 1

\section{O historiador}

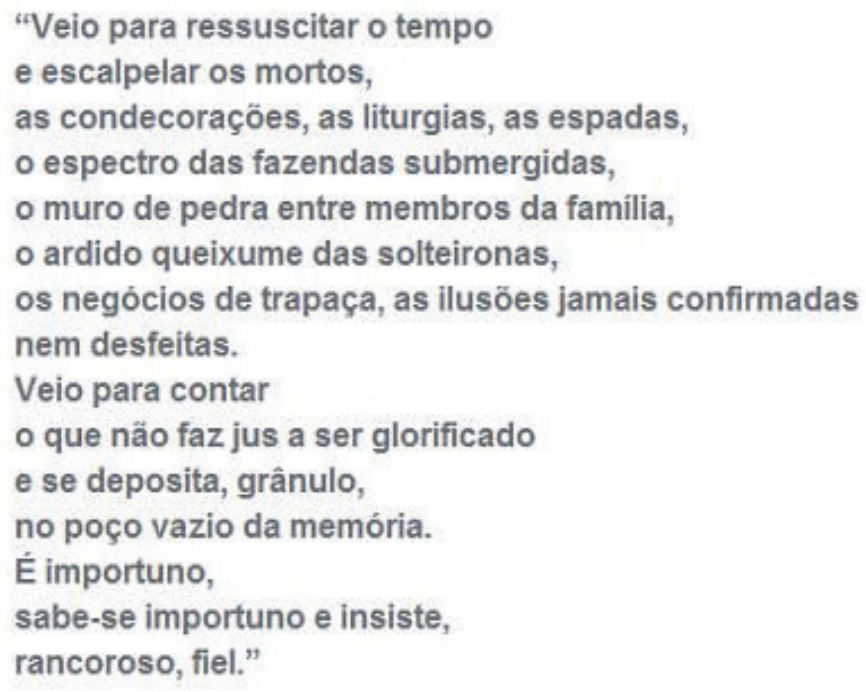

\section{Carlos Drummond de Andrade (1902-1987)}

Fonte: http://soprahistoriar.blogspot.com/2011/08/o-historiador-e-seu-dia19-de-agosto.html. Acesso em: 19 ago. 2011 
$\mathrm{Na}$ argumentação do poeta, o historiador por vezes é importuno, isso porque seria o responsável pela desmistificação dos ídolos e lendas nacionalistas e mais do que isso, por contar, ou seja, ensinar as "verdades" do passado. Por mais que consideremos o quanto o conceito de verdade é relativo, pois segundo Adam Schaff, o historiador não pode evitar a inserção do caráter subjetivo em suas pesquisas e portanto, a compreensão dos fenômenos se altera entre os historiadores. Esse caráter subjetivo da ciência histórica é o que nos permite conhecer várias faces de um mesmo fenômeno, o qual se constrói em sua totalidade a partir dessas leituras partidas ou realizadas a partir de inúmeros fragmentos do passado. Sendo assim, podemos perceber no poema que o historiador não é importuno apenas porque "ressuscita" os mortos, mas porque conta o que descobre em suas pesquisas. De acordo com Marc Bloch, "não deixa de ser menos verdade que, face à imensa e confusa realidade, o historiador é necessariamente levado a nela recortar o ponto de aplicação particular de suas ferramentas; em consequiência, a nela fazer uma escolha que, muito claramente, não é a mesma que a do biólogo, por exemplo; que será propriamente uma escolha de historiador” (p. 52). A relativização das verdades construídas no conhecimento histórico está intimamente atrelada justamente à escolha imposta por essas realidades confusas ou ainda pode chamar de complexificações contextuais, como apontado por Bloch, as quais o historiador se depara em todo o seu processo de pesquisa. Mas, essas escolhas não estão presentes apenas na prática do pesquisador, como também do próprio docente. Portanto, vemos que o ensino e a pesquisa são indissociáveis na profissão de Historiador.

Dessa forma, no processo de formação profissional do historiador, a docência é o seu espaço (não único, mas, mais expressivo atualmente) de atuação no campo do trabalho. Sobre a inserção no campo de trabalho, discorreu René Remond: "a profissão, para os historiadores, é geralmente o ensino: na nossa sociedade, raros, são os historiadores que não sejam professores" $(1987$, p. 312). Essa visão sobre o historiador pode ser percebida 
na fotografia de Sérgio Buarque de Holanda, o qual é representado entre livros. Essa representação é usualmente empregada ao profissional da História, o qual possui sua imagem ligada aos livros como instrumento de trabalho, como pode ser visto na figura número 2 e comparada com a representação do professor na figura número 3 .

Figura 2

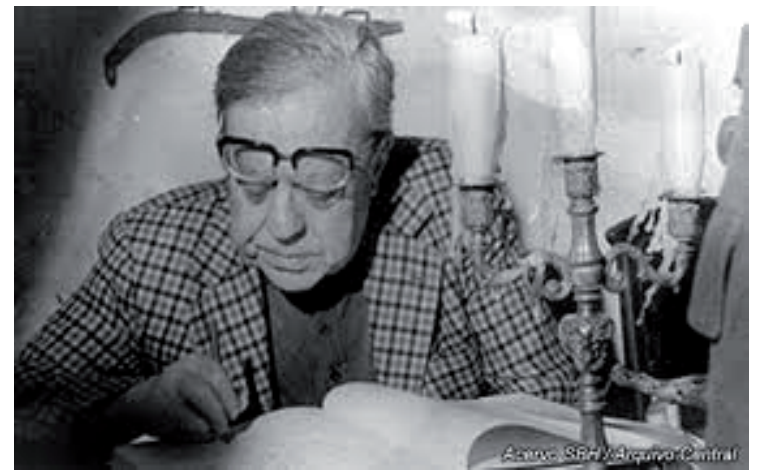

Fonte: http://www.siarq.unicamp.br/sbh/exposicoes.html. Acesso em: 25 ago. 2011.

Conforme vemos na figura número 2 , o historiador é representado entre os livros, como um erudito, mas essa imagem também é comum quando são feitas referências aos professores, de acordo com a figura número 3 : 
Figura 3

(C) ÓniginąílArtist

Reproduction rights, obtainable:from?

www Cartón'stock com

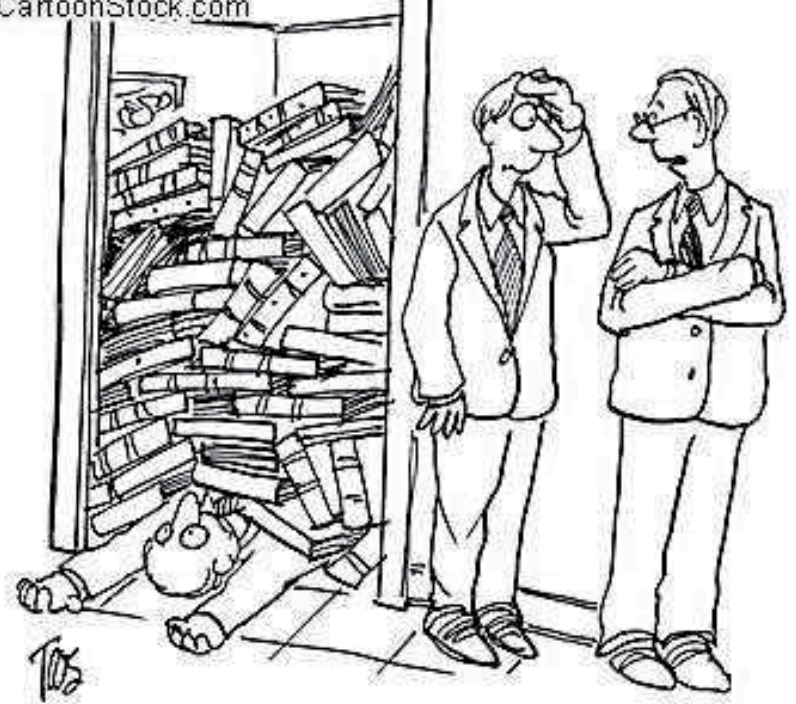

"I told you when you moved into Dr. Condee's office that his bookshelves were due to collapse any day."

Fonte: http://www.cartoonstock.com/directory/u/university_professor_gifts. asp. Acesso em: 09 out. 2011.

O colapso vivido pelo professor soterrado pelos livros demonstra o que afirmamos anteriormente, tanto o historiador quanto o professor são representados por sua relação com os livros. Essa imagem é comum tanto nos Estados Unidos, conforme a charge, e na França, como apontado na citação de Ferro, quanto no Brasil.

Sendo assim, esse panorama da sociedade francesa não se difere da realidade brasileira, pois, de acordo com Selva Guimarães Fonseca (2003, p. 86), "o campo de trabalho para os historiadores é o ensino, a profissão é o magistério [...]”. As Diretrizes 
Curriculares dos cursos de graduação em História, expresso no Parecer CNE/CES n ${ }^{\circ} 492$, de 3 de abril de 2001, aponta que as IES, através de formação continuada, devem oferecer aos profissionais da História "condições de suprir demandas sociais específicas relativas ao seu campo de conhecimento (magistério em todos os graus, preservação do patrimônio, assessorias públicas e privadas nos setores culturais, artísticos, turísticos, etc" (http://portal.mec.gov.br/cne/arquivos/pdf/CES0492.pdf, acesso em: 31 maio 2011). Entre as áreas de atuações dos profissionais com formação em História pode-se observar que o magistério em todos os níveis é o primeiro a ser apontado. Fonseca (2003) critica esse parecer, pois, para ela, nele está contido o silenciamento sobre a formação do historiador enquanto professor e estabelece um antagonismo entre a formação para a pesquisa e para a docência, como se ambas pudessem ser separadas. $\mathrm{O}$ professor somente terá habilidades para atuar no campo da magistério em todos os níveis, como estabelece o parecer, se em sua formação os conhecimentos em pesquisa e docência forem trabalhados em sua relação dialética.

A docência e a pesquisa histórica, quando propostas enquanto saberes imbricados, promovem a formação do profissional que chamaremos aqui de historiador-docente, o qual não é apenas um historiador que ministra aulas de história, mas é o pesquisador que, de forma engajada com a intervenção no campo social e histórico de seu tempo, transforma os resultados de seu fazer histórico em conhecimento ensinável, transmissível e aplicável no campo de compreensão do social. Afinal, os conhecimentos gerados pelas pesquisas no âmbito da História visam de forma geral fornecer subsídios para a construção de reflexões capazes de intervir nas múltiplas realidades, sejam sociais, culturais ou políticas, desde o local até o nacional. O historiador-docente é aquele que consegue em sua prática profissional aliar seus conhecimentos históricos, resultantes de suas pesquisas, à docência em história, com vistas a propiciar aos seus educandos um ambiente formativo voltado ao desenvolvimento de habilidades de análise, reflexão 
e crítica. Dessa forma, em concordância com Fonseca, o que se busca é "a superação da dicotomia forma/conteúdo, uma vez que não é possível conceber uma metodologia de ensino deslocada da produção do conhecimento específico. Logo, o objetivo é a compreensão da totalidade do ato de conhecer" (2003, p. 76). Essa totalidade do conhecimento é o próprio efeito da análise, da constituição de habilidades para a crítica do presente em relação ao passado. É um olhar que alcança a associação entre os conteúdos e os saberes práticos da vida cotidiana, que consegue transformar saberes históricos em conhecimentos aplicáveis para as relaçôes com o trabalho e a sociedade.

Nessa direção, entende-se que o saber histórico é a matériaprima do historiador-docente para a constituição de uma educação para a diversidade, seja ela religiosa, econômica, de gênero ou étnica, pois, de acordo com Marc Ferro (1983, p. 11), "não nos enganemos: a imagem que fazemos de outros povos, e de nós mesmos, está associada à História que nos ensinaram quando éramos crianças. Ela nos marca para toda a vida". Um ensino de História que vise o desenvolvimento de uma consciência para a vida em sociedade, problematizador e engajado com as realidades do presente, depende das formas como esses conhecimentos históricos serão trabalhados em sala de aula. Ao encontro dessa afirmação, segundo Jaime Pinsky e Carla Bassanzi Pinsky, "queiram ou não, é impossível negar a importância, sempre atual, do ensino de História. [...] A História é referência. É preciso, portanto, que seja bem ensinada” (2010, p. 19). Nessa citação, os autores chamam a atenção de que o conhecimento histórico não se faz por ele mesmo, não é a disciplina de História que contribui para a formação do sujeito pensante, mas o professor de História que apresenta, reelabora e propóe os saberes Históricos de forma que esses instrumentalizem seus alunos na arte de pensar.

Ainda segundo Ferro (1983), é preciso se levar em conta que o conhecimento do

passado não é apreendido de forma uníssona por todos, para cada sujeito ele promoverá múltiplas significações e se 
transformará no mesmo ritmo das mudanças vivenciadas pela sociedade. Nesse sentido, conforme discorreu George Snyders (1995), o professor é o responsável pelo fornecimento de uma espécie de matéria-prima, nesse caso o conhecimento histórico, para o desenvolvimento de habilidades para o raciocínio, da crítica e da reflexão, e mais importante que isso, o docente mostra ao educando que existe a possibilidade concreta de se raciocinar sobre a própria realidade.

Ainda nessa linha, afirmou Jean Vogler que a História enquanto disciplina tinha, no passado, como objetivo a construção de uma memória social. Segundo Le Goff, história e memória continuam interligadas por suas naturezas, em sua visão reconstruir a memória é tornar o tempo significativo. Portanto, a memória, seja ela individual ou coletiva, faz parte de um conjunto de fontes de instrumentos de trabalho que a história utiliza. Assim, paulatinamente as memórias se tornam elementos paralelos à história. Um exemplo disso pode ser observado nas sociedades cujos indivíduos possuem uma grande quantidade de informações em sua memória de longo e curto prazo, no que Jacques Le Goff chamou de "memória ativa” (LE GOFF, 1996). Dessa forma, essa capacidade de influência e contribuição para a formação das memórias coletivas da disciplina de História não ficou no passado. Para o autor, "a escola e, mais precisamente, o ensino de História têm um papel importante neste domínio. Toda a questão está em saber qual a memória social deve-se desenvolver hoje" (VOGLER, 1999, p. 6). O papel formativo dos saberes históricos, conforme apontado por Vogler, devem ser trabalhados de forma consciente pelo historiador-docente, ou seja, esse deve projetar os temas e valores que poderão ser depreendidos dos conhecimentos históricos ensinados.

O professor de História é o profissional que possui os saberes para propiciar aos educandos condições, ou mesmo um espaço de reflexão, que lhes permita adquirir as ferramentas necessárias para as vivências em sociedade. Nessa perspectiva, de acordo com Maria Auxiliadora Schmidt, vemos: 
O saber-fazer, o saber-fazer-bem, lançar os germes do histórico. Ele é o responsável por ensinar o aluno a captar e a valorizar a diversidade dos pontos de vista. Ao professor cabe ensinar o aluno a levantar problemas e a reintegrá-los num conjunto mais vasto de outros problemas, procurando transformar, em cada aula de História, temas em problemáticas $(2010$, p. 67$)$.

A disciplina de História não é informativa, como vulgarmente se pensa, mas formativa, ela é responsável, diante da prática do historiador-docente, por ensinar aos educandos a relação entre o passado e presente, a refletir sobre os problemas vivenciados em seu tempo e, principalmente a criar novas problemáticas de reflexão que lhes possibilitem intervir no campo social, transformando, como discorreu nossa autora na citação acima, temas da história e do cotidiano em problemáticas a serem pensadas. Portanto, ainda segundo Schmidt,

[...] ensinar História passa a ser, então, dar condições para que o aluno possa participar do processo do fazer, do construir a História. O aluno deve entender que o conhecimento histórico não é adquirido como um dom - comumente ouvimos os alunos afirmarem: 'eu não dou para aprender História' -, nem mesmo com uma mercadoria que se compra bem ou mal (2010, p. 57).

Constituir condições para a emancipação do aluno de forma que esse possa se perceber como um sujeito histórico, conforme discorreu Schmidt, é o próprio ato de oferecer instrumentos de empoderamento aos educandos. Esse se configura como uma ação coletiva desenvolvida entre o historiador-docente e sua turma de alunos, que transformam a sala de aula em um espaço privilegiado de decisões, de reflexão e de consciência social dos seus direitos como cidadãos. De acordo com Paulo Freyre (1992), essa consciência promovida pelo ato e ação de empoderamento do sujeito transcende a simples tomada individual de iniciativa, resolução e superação de situações reais e pontuais de suas vidas e lhes possibilita compreender as complexas teias das relações sociais próprias de cada contexto econômico e político, de forma a instrumentalizá-los a um olhar mais abrangente dos processos históricos nos quais se insere. Nessa direção, de acordo com 
Schmidt, "a aula de História é o momento em que, ciente do conhecimento que possui, o professor pode oferecer a seu aluno a apropriação do conhecimento histórico existente, através de uma atividade com a qual ele retome a atividade que edificou esse conhecimento" (2010, p. 57). É o espaço do público, do coletivo, mas também do fazer-se individual, como afirma a autora. No entanto, sabemos que esse é um processo que depende da emancipação e empoderamento do próprio professor de História. Isso porque, conforme afirmou Olavo Pereira Soares, "para ensinar, são necessárias determinadas habilidades, métodos, procedimentos de trabalho que possibilitem ao professor uma docência que resulte na compreensão e incorporação do aprendizado da História pelos seus alunos" (2008, p. 11). Entretanto, para o desenvolvimento dessas habilidades, elencadas pelo autor, o professor de História precisa compreender que deve ser mais do que um simples eco das produções de outrem, e seguir para o seu próprio entendimento como produtor e partícipe do conhecimento histórico. Afinal, para Schmidt, na sala de aula, diariamente o historiador-docente, ciente de seu papel como sujeito histórico, trava "um espetáculo impregnado de tensões em que se torna inseparável o significado da relação teoria e prática, ensino e pesquisa” (2010, p. 57).

Esse espetáculo de tensões, como a autora se refere às relaçôes professor-aluno, se estabelece diariamente em grande parte das salas de aula e somente a partir de uma reflexão sobre a prática do historiador-docente e da própria prática docente, se consegue pensar a sociedade. Dessa forma, para se poder analisar, mesmo que de forma superficial, determinada sociedade e sua educação têm-se que entender a ideologia dessa sociedade, sua visão de mundo. A visão de mundo de cada sociedade, seus dogmas e tabus são elementos pertencentes à ideologia. $\mathrm{O}$ Brasil, nesse sentido, não pode ser enquadrado em uma única ideologia. Assim, em uma mesma cidade, seus bairros possuem realidades diferentes e maneiras diferentes de encarar o mundo. Essa realidade nada uniforme, precisa ser compreendida para ser enfrentada pelo historiador-docente todos os dias. 
A sociedade atual tem aceitado pacificamente a influência $\mathrm{e}$ o papel educativo dos meios informatizados de comunicação. A televisão, a Internet, filmes e outros têm buscado cada vez menos acordar o cidadão desse coma em que o capitalismo o colocou. Entretanto, em contrapartida na sociedade da informação, os demais meios de comunicação como a Internet apresentam grandes quantidades de notícias e conteúdos que possibilitam a mobilização de diversos setores sociais. Se constitui aqui um binômio que revela as relações entre acomodação e mobilização. Essa posição não é para todos. As elites têm acesso aos meios necessários para a justificativa se seu status quo, formando a ideologia de cada sociedade. Mas não se pode afirmar que a ideologia é formada apenas de acordo com os interesses das classes dominantes. A educação familiar é a primeira a influenciar, formando a personalidade do indivíduo. "Da família à sociedade, a educação existe difusa em todos os mundos sociais, entre as incontáveis práticas dos ministérios do aprender; primeiro, sem classes de alunos, sem livros e sem professores especialistas; mais adiante com escolas, salas, professores e métodos pedagógicos" (BRANDÃO, 1995, p. 10).

Segundo José Carlos Libâneo, a desigualdade social, original do sistema econômico, determina as condições materiais do cidadão à sobrevivência, seu acesso a cultura e educação. Os trabalhadores recebem uma educação voltada para prepará-lo ao trabalho físico, sendo obrigados a conformar-se com uma educação deficiente. Os meios de educação são livremente utilizados para a disseminação, da ideologia dominante.

A prática educativa, portanto, é parte da dinâmica das relações sociais, das formas da organização social, suas finalidades e processos são determinados por interesses antagônicos das classes sociais. No trabalho docente, sendo manifestação da prática educativa, estão presentes interesses de toda ordem - sociais, políticos, econômicos, culturais - que precisam ser compreendidos pelos professores (LIBÂNEO, 1994, p. 21)

O papel do professor nesse contexto se destaca pelo papel que a educação exerce sobre o indivíduo. Esse segue recriando essa 
influência, estabelecendo uma relação dialética com o meio social. Essas influências são manifestadas através do conhecimento de cada indivíduo, em seus hábitos e costumes, e repassadas para as novas gerações que as recriam de acordo com sua realidade. As práticas de ensino precisam ser adaptadas de acordo com cada realidade. A tarefa central do professor, para que haja uma melhor inter-relação entre o conteúdo aprendido e a realidade social do aluno, é estabelecer tal ligação, fazendo com que o aluno analise seu meio, seu país e suas realidades político-econômicas.

Desta forma, para Libâneo, a sociedade atual é reflexo de seus educadores. A tarefa dos educadores é uma significativa contribuição para a formação crítica e criativa dos cidadãos, preparando-os para a participação ativa nas lutas pela transformação social.

Vê-se que a responsabilidade social da escola e dos professores é muito grande, pois cabe-lhes escolher qual concepçáo de vida e de sociedade deve ser trazida à consideração dos alunos e quais conteúdos e métodos lhes propiciam o domínio dos conhecimentos e a capacidade de raciocínio necessários à compreensão da realidade social e á atividade prática na profissão, na política, nos movimentos sociais (LIBÂNEO, 1994, p. 22)

Mas se a sociedade atual é reflexo dos educadores, de quem os educadores são reflexo? Responsabilizar o docente é fácil, mas não é suficiente. É necessário que se trate os educadores como pessoas que estão inseridas na mesma realidade do aluno. Durante várias décadas, no Brasil, a ditadura reprimiu a liberdade de pensamento. Foram décadas de repressão ao aluno, mas também ao professor. A alienação existente hoje, tanto dos professores quanto dos alunos, é reflexo dessa repressão (MONTEIRO, 2007).

Hoje a grande tarefa é fazer o aluno pensar criticamente, mas quem levará o professor a pensar criticamente? A meu ver, a grande tarefa do professor e da escola nos dias de hoje é desatar as amarras da ditadura. O período da repressão já passou há muito, as escolas e os docentes já passaram por esse processo de libertação. Mas a realidade não diz isso. $\mathrm{O}$ professorado ainda 
continua preso à ideologia do silêncio e do não questionamento. Enquanto os professores e as escolas não desfizerem as ataduras do silêncio, não será possível o emprego de novos métodos de ensino que levem o aluno a pensar criticamente.

A partir dessa reflexão, podemos nos questionar: mas como é possível o professor de História constituir, em sua prática docente, espaços de emancipação dos sujeitos através do ensino pela pesquisa e da pesquisa pelo ensino, se ele mesmo não possui as habilidades para tal? As competências docentes necessárias para a constituição de um ensino para a pesquisa dependem não apenas das vivências de ensino-aprendizagem dos professores, de sua experiência profissional tanto em sala de aula, quanto em pesquisa, mas, principalmente, de uma formação que não o restrinja a conhecimentos específicos e, sim, o lance em debates mais amplos das áreas das Ciências Humanas.

Devemos chamar atenção aqui para o fato de que utilizar conhecimentos históricos não implica a simples aplicação de regras. Na verdade, empregar suas competências para solução de problemas reais é a capacidade de emprego dos mais variados recursos, de forma inovadora, criativa e singular, adequados ao que a situação exige. Assim, o conceito de competência reúne, em si, um conjunto de que Perrenoud (2002) chama de esquemas, ou seja, uma estrutura que não varia de uma operação ou ação, mas que sofre adequaçóes conforme o contexto.

Quando consultamos nossos principais documentos da área de ensino, sobre o que eles nos propõem acerca das competências e habilidades, percebemos que suas definições também estão ligadas a conhecimentos e capacidades.

Nos Parâmetros Curriculares Nacionais (PCNs), encontramos os deveres de cada instância educacional. A Federação deve ter em comum as diretrizes curriculares e parâmetros curriculares de forma que esses indiquem linhas gerais de atuação e concepção pedagógica para o sistema de ensino em todo o país, visando a um ensino centrado no desenvolvimento das competências e habilidades, voltadas à formação contextualizada do cidadão. Aos 
Estados fica delegada a tarefa de definir seus próprios currículos educacionais e os municípios ou escolas devem elaborar seus programas voltados a atender suas especificidades locais e contextos sócio-econômicos regionais. Assim, do macro para o micro, o ensino brasileiro visa ao desenvolvimento de competências e habilidades do educando.

De forma mais precisa, nas diretrizes traçadas pela Conferência Mundial de Educação para Todos, realizada em Jomtiem na Tailândia, pela UNESCO, em 1990, encontramos quatro pilares da educação que deveriam ser meta de desenvolvimento em todos os países signatários: 1. Aprender a conhecer; 2. Aprender a fazer; 3. Aprender a viver com os outros; 3. Aprender a ser. Os pilares educacionais apresentados pela UNESCO nos reportam diretamente ao desenvolvimento de competências e habilidades. Nesse sentido, segundo Fleury e Fleury (2001, p. 184),

[...] a noção de competência aparece assim associada a verbos como: saber agir, mobilizar recursos, integrar saberes múltiplos e complexos, saber aprender, saber engajar-se, assumir responsabilidades, ter visão estratégica. Do lado da organização, as competências devem agregar valor econômico para a organização e valor social para o indivíduo.

A questão que se abre a partir da análise de Fleury e Fleury é pensar que tipo de competências e habilidades trabalharemos para que nossos alunos desenvolvam através do ensino de História. Habilidades voltadas ao mercado? Que visem sua formação profissional e inserção no campo de trabalho? Ou aquelas voltadas para a vida em sociedade, respeito, tolerância e capacidade de solução de problemas? Qualquer professor responderia que almejaria a soma dos dois, pois projeta a educação como aquela que oferecerá condições para o educando se desenvolver plenamente, com habilidades e competências para sua inserção no mercado de trabalho e ao mesmo tempo, para uma vida crítica e reflexiva em sociedade.

No entanto, quando observamos as definições de competências e habilidades podemos notar que essas não podem ser desenvolvidas pelo professor na vida do aluno, ao contrário, é 
o próprio educando que as desenvolve. Dessa forma, cabe ao professor de História, ou seja, o historiador-docente, apenas instrumentalizar seus alunos de forma que encontrem as condições "contextuais, geográficas e climáticas" ideais para desenvolverem suas habilidades e, dessas, suas competências.

Para explicar melhor esse processo poderíamos imaginar um médico cirurgião na sala de cirurgia diante de seu paciente. Antes de iniciar o processo operatório, a enfermeira-chefe se posiciona ao seu lado com uma bandeja com os instrumentos, bisturis, etc., todos esterilizados e organizados em ordem. O médico, ao iniciar a cirurgia, estende a mão e a enfermeira lhe alcança o bisturi para a primeira incisão... Bem, ao olharmos essa cena, podemos perguntar, no sentido figurado, se a cirurgia fosse o processo de ensino-aprendizagem, quem representaria o professor e quem representaria o aluno? Muitos poderiam responder de imediato, o médico é o professor e a enfermeira o aluno! Mas, se pararmos para refletir sobre o que é o processo de ensino-aprendizagem, notaremos que, na verdade, o professor é o enfermeiro e o médico é o aluno, pois quem realiza a aprendizagem é o educando e o docente apenas lhe oferece os instrumentos para tal realização.

Os professores não são absolutos, "super" poderosos ou onipotentes, capazes de FAZER um aluno aprender. Quem aprende é o aluno! Nós, professores, somos os mediadores ou até poderíamos dizer que somos a bússola que aponta o caminho, quem escolhe segui-lo é o discente. Sendo assim, no processo de desenvolvimento das competências e habilidades, cabe ao professor criar condiçôes ideais para o aluno se desenvolver.

Nesse ínterim, o historiador-docente deve encontrar na formação continuada o espaço do que podemos chamar de "arejamento" ou seja, de ventilação, renovação, reflexão e análise de suas próprias vivências de ensino-aprendizagem de História, se teletransportando do estigma de "eco da historiografia vigente" para o campo de produtor do conhecimento. A formação do professor de História não encontra seu fim na graduação, pelo 
contrário, segundo Soares, “ensinar implica aprender os princípios e conteúdos de sua disciplina, aprender sobre as aprendizagens dos alunos e sobre as possibilidades de estas aprendizagens serem ou não significativas” (2008, p. 12). Os conhecimentos históricos estão em constante atualização e revisão, por isso, como apontou Soares, o ensino de História depende do constante aprimoramento do professor.

A formação continuada de professores de História, tão essencial para seu empoderamento e habilitação para um ensinopesquisa, ainda está distante da realidade de muitos docentes de História, conforme afirma Schmidt:

Formado, o professor de História, como tantos outros, envolve-se em encargos familiares, com a luta pela sobrevivência e quase sempre não dispõe de tempo e nem de dinheiro para investir em sua qualificação profissional. Seu cotidiano é preenchido com múltiplas tarefas; seu tempo de viver é fragmentado, dilacerado pelas preocupações muitas vezes contraditórias entre sua profissão, família e progresso cultural (2010, p. 55).

Esse dilaceramento promovido pelo dia a dia da profissão de professor afasta, como bem discorreu a autora, o historiadordocente dos espaços acadêmicos, de sua promoção cultural e até conhecimentos de novos métodos, teorias e experiências de ensino-aprendizagem apresentadas em pesquisas recentes. Quanto mais atua, mas distante fica das novas abordagens e diálogos sobre os saberes históricos. Dentro desse contexto, conforme afirma Kátia Maria Abud,

[...] o livro didático é quase que o único material de apoio que o professor encontra à sua disposição e, por isso, apóia nele a parte central do seu trabalho - planeja as aulas seguindo a disposição dos conteúdos, utiliza os textos em sala de aula, monta com eles um material próprio e deles retira questões de avaliação. A ausência de projetos de formação continuada, de reuniões de professores, de discussões sobre seu trabalho acentua a dependência do manual (2007, p. 115).

O historiador-docente distanciado dos espaços de reflexão muitas vezes vê sua prática esvaziada de outros suportes de 
reflexão e fica dependente de seus manuais didáticos. Aqui não criticamos a utilização do livro-didático em sala de aula, muito pelo contrário, o que criticamos é a dependência, a simplificação e o condicionamento do ensino de história, resultantes do dilaceramento do historiador-docente. Não podemos separar os conhecimentos históricos considerados acadêmicos daqueles ensinados na escola. De acordo com Allieu (1995), separar a análise da disciplina de História ensinada no espaço escolar formal dos debates acadêmicos é

[...] artificial e mutilante. Artificial porque suas gêneses se entrecruzam. A segunda metade do século XIX viu nascer uma disciplina que se constitui ao mesmo tempo em ciência e como objeto ensinável e, também, objeto a ensinar ... Mutilante porque História de referência e História escolar fazem parte de um sistema produzido pelos homens de uma mesma época. Dissociá-los nos parece esvaziar a História de sentido ( ALLIEU, 1995, p. 124-125). ${ }^{1}$

Portanto, conforme a reflexão do autor, a indissociação entre os conhecimentos históricos acadêmicos e os escolares é um importante instrumento para o repensar a História enquanto disciplina escolar. Essa tarefa se projeta em, conforme afirmou Elza Nadai e Circe Bittencourt, uma parada, ou seja, um tempo para a reflexão sobre pontos estruturantes do conhecimento histórico que transcendem os conteúdos, suas metodologias de ensino e teorias. De acordo com as autoras, "trata-se de refletir sobre o sentido político e social da disciplina histórica" (NADAI; BITTENCOURT, 2011, p. 94). No entanto, para essa reflexão é importante que sejam oferecidas ao historiadordocente condições e espaço de estudo e aprimoramento de seus conhecimentos. Afinal, conforme afirmaram Pinsky e Bassanezi Pinsky, "mais do que o livro, o professor precisa ter conteúdo.

1 “.... artificielle et mutilante. Artificielle parce que leurs origines sont intimement liés. La seconde moitié du XIXe siècle a vu la naissance d'une discipline qui est à la fois un objet de la science et propices à l'apprentissage, et également l'objet d'enseigner ... Histoire mutiler parce que la référence et enseignement de l'histoire font partie d'un système produit par les hommes de la même époque. Dissocier eux semble idée claire de l'histoire" (ALLLIE, 1995, p. 124-125). 
Cultura. [...] Sem estudar e saber a matéria não pode haver ensino" (2010, p. 2). A formação continuada de professores, fundamentalmente através da inserção e ingresso dos docentes de História atuantes no ensino fundamental e médio em Programas de Pós-graduação stricto sensu, cursos de especialização ou de extensão, não apenas contribuem para que o professor conheça melhor as bases e conceitos dos saberes históricos, mas, principalmente para sua revalorização enquanto profissional. Os professores são responsáveis socialmente perante os alunos, de acordo com Pinsky e Bassanezi Pinsky, “... preocupando-se em ajudá-los a compreender e - esperamos - a melhorar o mundo em que vivem" (2010, p. 22). Mais do que nunca, é de fundamental importância a formação continuada de professores, pois não adianta pensar em um ensino de qualidade se ainda podem ser encontrados, muitas vezes, nas salas de aula, de acordo com Pinsky e Bassanezi Pinsky, professores mal preparados e desmotivados, que não conseguem ministrar boas aulas, “... ao passo que um bom professor pode até aproveitar-se de um livro com falhas para corrigi-las e desenvolver o velho e bom espírito critico entre os seus alunos" (2010, p. 22).

Diante dessa reflexão e a partir do comprometimento com a superação da realidade que tem estabelecido distanciamentos entre os historiadores-docentes e os Programas de Pós-graduação stricto sensu, através da articulação do processo de ensino e aprendizagem com as exigências de qualificação do corpo docente, decorrentes das transformações da sociedade, dos conhecimentos históricos e dos avanços das novas linguagens das tecnologias da informação, propomos a reflexão sobre a formação continuada de professores centrada no desenvolvimento de competências em conteúdos da História, da pesquisa e das vivências de ensino-aprendizagem necessárias ao exercício da função do historiador-docente.

Portanto, a formação continuada de professores de História deve visar ao desenvolvimento de habilidades e competências para a construção de reflexões sobre a cidadania, a profissionalização e 
a responsabilidade social, assim como o aprimoramento de uma cognição histórica.

Primeiramente, para se pensar em um ensino de História voltado para o desenvolvimento de habilidades e competências, é preciso refletir sobre as palavras de Regina Bastos Leal: "O que é importante, do ponto de vista do ensino, é deixar claro que o professor necessita planejar, refletir sobre sua ação, pensar sobre o que faz, antes, durante e depois" (LEAL, 2009, p. 01). Planejar o processo de ensino é o primeiro passo para se alcançar os possíveis objetivos almejados para a educação. Esse planejamento deve partir das seguintes perguntas: Quais habilidades meus alunos devem desenvolver? Quais capacidades eles precisam para viver em sociedade? Essas questóes devem nos guiar na hora de planejar as atividades, conteúdos e metodologias a serem empregadas durante o ano letivo. Mas, e os conteúdos? Eles devem ser os meios pelos quais os alunos desenvolverão suas competências.

Eis o desafio, constituir um ensino capaz de, a partir dos conteúdos, instrumentalizar meu aluno a desenvolver suas habilidades e competências. Como fazer isso? Segundo Jorge Larrosa (2006), todo o processo de ensino e aprendizagem depende da relação entre experiência e sentido. Para o autor, experimentar os conteúdos é indispensável para a constituição do aprendizado. No entanto, podemos nós, professores de História, afirmar: como experimentar o que é passado? Como sentir o que não existe mais? Não há como reviver o passado, com certeza, mas através do conhecimento do passado podemos vivenciar experiências.

$\mathrm{O}$ aprendizado é resultado das experiências vivenciadas e das lembranças adquiridas durante o processo de formação identitária do sujeito. Precisamos compreender o processo de aprendizagem ancorado na experiência, segundo Fleury e Fleury, como

[...] um processo neural complexo, que leva à construção de memórias. Aquilo que se aprende e depois se esquece é como se nunca tivesse acontecido; o conjunto de coisas de que nos lembramos constitui a nossa identidade. Como o coloca Izaquierdo (1997), o indivíduo é exatamente só aquilo de que se lembra; eu sou quem sou porque me 
lembro de quem sou, porque sei quem sou. Se não nos lembrássemos de nada, não seríamos alguém; por isso é tão trágica a fase final da doença de Alzheimer, ou a ignorância do próprio eu (FLEURY; FLEURY, 2001, p. 190).

Esse processo de associação entre o aprendizado e a lembrança é em parte resultado da própria mimese, ou seja, memória constituída a partir da experiência frente aos fenômenos. No ensino de História, podemos construir experiências que possibilitem ao aluno vivenciar os fatos de outras formas que não seja voltar ao passado em uma máquina do tempo, sonho de muitos historiadores, mas que só é possível no cinema como no filme de mesmo nome, estrelado por Guy Pearce, lançado no ano de 2002.

Primeiramente, precisamos diferenciar em nossos planejamentos as naturezas de objetivos. Sabemos que existem três tipos de objetivos principais: os conceituais (saber conhecer), os procedimentais (saber fazer) e os atitudinais (saber ser). Podemos perceber que esses três tipos de objetivos nos reportam diretamente para as competências e habilidades elencadas pela UNESCO como as metas do ensino básico dos países signatários.

No entanto, sabemos que ao traçarmos nossos programas, estamos normalmente preocupados com apenas um dos tipos de objetivos, o conceitual, saber conhecer, como se o conhecimento por si somente pudesse proporcionar ao educando o ambiente propício para que desenvolva suas competências e habilidades. Tal comportamento leva a uma premissa falseada, ou podemos dizer falaciosa, proposta por nossos pais iluministas: "O conhecimento liberta da escuridão da ignorância”.

Agora, sob nova roupagem, podemos afirmar que o que aprendo a fazer com o conhecimento é que me liberta da escuridão do preconceito, dos tabus, da violência e da exploração, e não simplesmente o saber pelo saber.

Dessa forma, mais do que nunca, nós, professores de história, precisamos propor atividades que visem aos demais tipos de objetivos, como os procedimentais. Se eu não propuser trabalhos de escrita, meu aluno não aprenderá a fazer artigos, crônicas, 
redações e outros textos; se eu não propuser atividades de análise social, como entrevistar moradores de rua, visitar hospitais, consultar jornais atuais e antigos, meus alunos não desenvolverão posturas frente aos acontecimentos do presente e do passado. São novas atitudes frente ao contexto geral que almejamos que nossos alunos desenvolvam, mas se não proporcionamos atividades que lhes propicie um ambiente favorável, isso será impossível.

Algumas propostas são viáveis, como: análise de jornais, pesquisas de campo, estudos de imagens, filmes, entrevistas com pais, indivíduos da sociedade, ouvir emissoras de rádio, construir blogs, criar jogos, entre tantas outras possibilidades. Essas atividades são todas de cunho avaliativo, porque criar condiçôes de autoconstrução requer processo de avaliação do desenvolvimento do sujeito dentro da determinada atividade.

Portanto, esse texto nasceu da percepção que o ensino de História vem sofrendo nas últimas décadas uma crise de esgotamento. $\mathrm{O}$ mais comum entre alunos da educação básica é ouvir que os mesmos não gostam de história. Mas, por que isso ocorre? A resposta é simples, por falta de sentido. Significar o ensino é a essência do processo de ensino e aprendizagem, entretanto, o desafio é fazer isso. Superar os obstáculos do ensino de História propostos pelo cotidiano escolar é uma tarefa difícil quando o aluno não percebe a significação do que estuda e principalmente não se vê como agente desse processo histórico. $\mathrm{O}$ desafio do professor é

[...] mostrar que, graças à cultura que nós, membros da espécie humana, produzimos, temos tido talento para nos vestir mais adequadamente que os ursos, construir casas melhores que o joão-de-barro, combater com mais eficiência que o tigre, embora cada um de nós, seres humanos, tenha vindo ao mundo desprovido de pelos espessos, bicos diligentes ou garras poderosas (PINSKY; BASSANEZI PINSKY, 2010, p. 21).

A partir de um ensino de História engajado com a construção de um conhecimento para a vida prática, como proposto no citado, o discente seria capaz de se compreender enquanto sujeito histórico, interventor e transformador das realidades contextuais de seu tempo. 
Dessa forma, na mesma direção apontada por Marta Gouveia de Oliveira Rovai (1995); Antônio Simplicio de Almeida Neto (2002) e Maria Rocha Rodrigues (2003), não se pode explicar o fracasso escolar com críticas à competência docente. Para esses autores, em contraposição a uma tendência explicativa simplista, deve-se perceber que não existe fracasso escolar, mas alunos e professores que vivenciam a situação de fracasso escolar. Nesse sentido, concordamos com Charlot quando propõe que a única forma de superação do fracasso escolar é o desenvolvimento de "uma relação de um sujeito com o mundo, com ele mesmo e com os outros. É relação com o mundo como conjunto de significados, mas, também, como espaço de atividades, e se inscreve no tempo" (2000, p. 78$)$. Essa relaçã̃o do sujeito com o mundo e com ele mesmo é o seu empoderamento, o seu desenvolvimento de habilidades que the possibilitem o pleno exercício da cidadania. Portanto, a situação de falência de uma educação histórica voltada ao desenvolvimento pleno da cidadania, segundo Izabel Barca, não possui uma solução infalível. No entanto, é sabido que é preciso fazer um profundo investimento em ações que visem ao aprimoramento da formação docente. Para Barca,

[...] alguns modelos e versões da História são mais atualizados do que outros, alguns temas e escalas de abordagem adquirem mais relevância para responder a problemas da sociedade de hoje do que outros. A adopção de um modelo de História narrrativa-explicativa, que integre uma análise fundamentada de perspectivas diversas, que não esqueça a escala local e global, parece ser mais consentânea com os debates sobre a ciência histórica e com as exigências de desenvolvimento, no respeito por várias identidades (BARCA, 2007, p. 6).

$\mathrm{Na}$ visão da autora, é necessário investimento em uma proposta de formação de professores de História que adote um modelo de História narrativa-explicativa, ou seja, que através da aplicação de pesquisa no ensino se valorize os conhecimentos históricos tanto globais, quanto locais, de forma a contribuir para o desenvolvimento da cidadania em respeito a diversidade identitária. 
Dessa forma, constituir um ensino de história que privilegie a pesquisa, o pensamento reflexivo e crítico, objetivos perseguidos pelos historiadores-docentes, é um processo que deve aliar teoria e prática, constituindo o que podemos conceituar como uma práxis docente. Mas, essa práxis, deve ser voltada à formação do sujeito pensante livre e não centrada conforme discorreu Michel Foucault (1989), em um profundo investimento de adestramento do sujeito para sua inserção no campo social.

Esse tipo de visão pode parecer voltado estritamente para a linha de formação de professores excluindo a formação profissional do historiador, no entanto, sabemos que no Brasil, a profissionalização do historiador passa há muitas décadas primeiro pela docência, como já referido, pois, a inserção do profissional da História em ouras atividades, como centros de referência em Pesquisa, orientações voltadas a questões patrimoniais e outros campos, ainda é insipiente. A grande maioria dos egressos dos cursos de História, sejam licenciados ou bacharéis, seguirão a carreira docente, seja em nível fundamental e médio ou superior. Nessa perspectiva, discorrer sobre o ofício do historiador sem perpassar profundamente uma reflexão sobre sua atuação na docência é ignorar seu maior campo de atuação.

\section{Referências}

ABUD, Kátia Maria. A História nossa de cada dia: o saber escolar e o saber acadêmico na sala de aula. In: MONTEIRO, Ana Maria; GASPARELLO, Arlete Medeiros; MAGALHÃES, Marcelo de Souza. Ensino de História: sujeitos, saberes e práticas. Rio de Janeiro: Mauad X, 2007, p. 107-117.

ALLIEU, Nicolle. De l'Histoire dês chercheurs à l'Histoire scolaire. In: DEVELAY, Michel. Savoirs scolaires et didactique dês disciplines: une encyclopédie pour aujourd'hui. Paris: ESF Editeur, 1995.

BARCA, Isabel. Educação Histórica: Uma nova área de investigação. In: ARIAS NETO, José Miguel (Org.). Dez anos de pesquisa em ensino de História. Londrina: AtritoArt, 2005, p. 15-25. 
BARCA, Isabel. Aula Oficina: um projecto à avaliação. In: BARCA, Isabel (Org.). Para uma educação histórica com qualidade. Braga: Uminho, 2004, p. 131-144.

BLOCH, Marc. Apologia a História ou o ofício do historiador. Rio de Janeiro: Editora Jorge Zahar, 2001.

BRANDÃO, José Carlos. O que é educação? São Paulo: Brasiliense, 1995.

CHARLOT, Bernard. A noção de relação com o saber: bases de apoio teórico e fundamentos antropológicos. In: CHARLOT, Bernard (Org.). Os jovens e o saber. Porto Alegre: Artmed, 2001, p. 11-31.

CHARLOT, Bernard. Da relação com o saber. Elementos para uma teoria. Porto Alegre: Artmed, 2000.

FERRO, Marc. A manipulação da história no ensino e nos meios de comunicação. São Paulo: Ibrasa, 1993.

FONSECA, Selva Guimarães. Didática e prática de ensino de História. Campinas: Papirus, 2003.

FOUCAULT, Michel. Microfisica do poder. Rio de Janeiro: Graal, 1989.

FREIRE, Paulo. Pedagogia da Esperança: um encontro com a pedagogia do oprimido. Rio de Janeiro: PAZ e TERRA, 1992.

LARROSA, Jorge. Pedagogia Profana - Danças, piruetas e mascaradas. Belo Horizonte: Autêntica, 2006.

LEAL, Regina Barros. Planejamento de ensino: peculiaridades significativas. In: Revista Iberoamericana de Educación. ISSN: 16815653. Disponível em: <http://www.rieoei.org/deloslectores/1106Barros. pdf $>$. Acesso em: 14 maio 2011.

LE GOFF, Jacques. História e Memória. Campinas: Ed. UNICAMP, 1996.

LIBÂNEO, José Carlos. Didática. São Paulo: Cortez,1994.

MONTEIRO, Ana Maria; GASPARELlO, Arlete Medeiros; MAGALHÃES, Marcelo de Souza. Ensino de História: sujeitos, saberes e práticas. Rio de Janeiro: Mauad X, 2007. 
NADAI, Elza; BITTENCOURT, Circe. Repensando a noção de tempo histórico no ensino. In: PINSKY, Jaime. O ensino de história e a criação do fato. São Paulo: Contexto, 2011, p. 93-120.

NETO, Antônio Simplício de Almeida. Dimensões utópicas nas representações sobre o ensino de história: memórias de professores. Tese de doutorado: FEUSP, 2002.

PERRENOUD, Philippe. A prática reflexiva no oficio de professor: profissionalização e razão pedagógica. Porto Alegre: Artmed, 2002.

PINSKY, Jaime; PINSKY, Carla Bassanezi. Por uma História prazerosa e conseqüente. In: KARNAL, Leandro (Org.). História na sala de aula: conceitos, práticas e propostas. São Paulo: Contexto, 2010, p. 17-36.

PINSKY, Jaime. O ensino de história e a criação do fato. São Paulo: Contexto, 2011.

REMOND, René. O contemporâneo do contemporâneo. In: CHAUNU, Pierre et al. Ensaios de ego-história. Lisboa: Edições 70, 1987. p. $287-$ 342.

RODRIGUES, Gabriela; PADRÓS, Enrique Serra. História Imediata e pensamento único: reflexões sobre a História e o ensino de História. In: LENSKIJ, Tatiana; HELFER, Nadir Emma. A memória e o ensino de história. São Leopoldo: ANPUH/RS, 2000, p. 123-139.

ROVAI, Marta Gouveia de Oliveira. Os meios de comunicação de massa nas aulas de história. In: Revista comunicação e educação. São Paulo: USP/Moderna, 1995, p. 81-87.

SCHMIDT, Maria Auxiliadora. A formação do professor de História e o cotidiano da sala de aula. In: BITTENCOURT, Circe Maria Fernandes. O saber histórico na sala de aula. São Paulo: Contexto, 2010, p. 54-66.

SCHAFF, Adam. "Descrição - Explicação - Avaliação" In: SCHAFF, Adam. História e verdade. São Paulo: Martins Fontes, 1995.

SNYDERS, George. In: KLEIN, Luiz Fernando. Entrevista com o Prof. Georges Snyders. Revista da Faculdade de Educação [on-line]. 1995, v. 21, n. 2, p. 139-147. Disponível em: <educa.fcc.org.br/scielo.php?scri pt...25551995000200009... >. Acesso em: 12 jul. 2011 
SOARES, Olavo Pereira. A atividade de ensino de história: processo de formação de professores e alunos. Araraquara, SP: Junqueira \& Marin editores, 2008.

VOGLER, Jean. Pourquoi enseigner l'histoire à l'école? Paris: Hachette, 1999. 